Received: 26 June 2019

Revision received: 22 August 2019

Copyright $\odot 2019$ ESTP

Accepted: 26 August 2019

www.estp.com.tr

DOI 10.12738/estp.2019.4.002 • October $2019 \cdot 19(4) \cdot 14-33$

Review article

\title{
Four Pedagogical Dimensions for Understanding Flipped Classroom Practices in Higher Education: A Systematic Review
}

\author{
Joyce Hwee Ling Koh \\ University of Otago, New Zealand
}

\begin{abstract}
Despite being widely adopted in higher education to support student-centred learning, the pedagogical design of flipped classrooms has been criticised as lacking in theoretical framing. This study proposes that the pedagogical dimensions of personalisation, higher-order thinking, self-direction, and collaboration can be used as theoretical lenses to deconstruct how flipped classroom practices support student-centred learning. Through a systematic review of 56 cases from 51 studies of flipped learning implementation published in peer-reviewed articles, this study found that flipped classrooms personalise learning through resource and teacher access, develops higher-order thinking through problemsolving, and engages students in collaborative learning through both peer groups and design groups. Trends of positive student learning outcomes are more consistent among cases that support collaborative learning and student selfdirection of learning performance review by repeated application and remediation. Nevertheless, majority of the cases reflect students having limited personalisation of learning choice and structured collaborative processes are seldom used apart from the few cases implementing team-based learning. The theoretical applications of the four pedagogical dimensions as well as the implications for the future research and practice of flipped classrooms are discussed.
\end{abstract}

\section{Keywords}

Flipped classrooms $\bullet$ flipped learning $\bullet$ blended learning $\bullet$ higher education $\bullet$ student-centred learning

Correspondence to Joyce Hwee Ling Koh, PhD, Higher Education Development Centre, University of Otago, New Zealand. Address: $65-75$ Union Place West PO Box 56, Dunedin 9054, New Zealand. E-mail: joyce.koh@otago.ac.nz. Telephone: 64-3-479-7232. Fax: 64-3-479-8362

Citation: Koh, J. H. L. (2019). Four pedagogical dimensions for understanding flipped classroom practices in higher education: A systematic review. Educational Sciences: Theory and Practice, 19(4), 14 - 33. http://dx.doi.org/10.12738/estp.2019.4.002 
Practices of flipped classrooms have existed in higher education as "inverted classrooms" (e.g., Lage, Platt, \& Treglia, 2000) before the term "flipped classrooms" was created by Bergmann (2012). Flipped classrooms generally refer to the instructional practice where lecture content is made available online for pre-class study and in-class learning activities are used to deepen content understanding (Betihavas, Bridgman, Kornhaber, \& Cross, 2016; Brewer \& Movahedazarhouligh, 2018; Lage et al., 2000; O'Flaherty \& Phillips, 2015; Presti, 2016; Seery, 2015). The traditional approach of lecturing during class and students doing practice exercises independently outside class is therefore "inverted" or "flipped". With its use of online resources to support pre-class study, flipped classrooms have also emerged as a model of blended learning that is taking hold in higher education institutions in a survey by Educause where about $17 \%$ of 338 individuals from different higher education institutions reported their institutions being current adopters of flipped learning (Grajek, 2016).

Flipped classrooms are generally considered to be student-centred (Akçayır \& Akçayır, 2018; Lin \& Hwang, 2018) but the pedagogy lacks clear reference to educational or learning theories (Lundin, Bergviken, Hillman, Lantz-Andersson, \& Peterson, 2018). While the wide spectrum of pedagogical practices that can be considered as student-centred provides lecturers with a plethora of implementation possibilities, it also leaves them with little guidance on how to apply these with respect to flipped classrooms (Karabulut-Ilgu, Jaramillo, \& Jahren, 2018). The practice of flipped classrooms is observed to be "undertheorized" (Abeysekera \& Dawson, 2014, p. 2). Consequently, systematic reviews of higher education flipped classrooms call for stronger pedagogical theorisation of its practices (e.g., Brewer \& Movahedazarhouligh, 2018; Lundin et al., 2018; O'Flaherty \& Phillips, 2015).

Student-centred learning is contrasted with teacher-directed and transmission-based learning (Neumann, 2013; Tangney, 2014) as it emphasises active learner engagement and deep learning (Cannon \& Newbie, 2000; Howland, Jonassen, \& Marra, 2013; Lea, Stephenson, \& Troy, 2003). This study draws upon the ideas of student-centred learning to define four pedagogical dimensions that are pertinent to higher education flipped classrooms. These dimensions are then used as lenses for a systematic review of 51 empirical peer-reviewed studies of higher education flipped classroom. The gaps in current practices as well as the implications for the practice and research of flipped classrooms are discussed.

\section{Student-Centred Learning and Pedagogical Dimensions of Flipped Classrooms}

Student-centred learning implies that students are at the heart of the learning experience (Alexander \& Murphy, 1998; Taylor, 2013). Student-centred learning focuses on individual interest and choice by considering student flexibility and autonomy. Consequently, greater personal responsibility and active engagement are demanded of students (Kember \& Wong, 2000; Lea et al., 2003; Neumann, 2013; Taylor, 2013). Student-centred learning is also observed to be tightly connected with the ideas of constructivism (Neumann, 2013; Tangney, 2014) as it advocates learning practices that support students to construct knowledge for understanding and deep learning (Lea et al., 2003; Tangney, 2014), especially within the contexts of authentic problem-solving and real-world work preparation (Hannafin, Hill, \& Land, 1997; Howland et al., 2013; Lea et al., 2003). Student-centred learning can be enacted through increased partnership between students and teachers (Neumann, 2013) and collaboration among peers (Howland et al., 2013).

An analysis of conceptual studies (Abeysekera \& Dawson, 2014; Flipped Learning Network, 2014; Lage et al., 2000) and systematic reviews of higher education flipped classrooms (Akçayır \& Akçayır, 2018; Betihavas et al., 2016; Brewer \& Movahedazarhouligh, 2018; Chen, Lui, \& Martinelli, 2017; Karabulut- 
Ilgu et al., 2018; Lin \& Hwang, 2018; Presti, 2016; Seery, 2015) suggest that four pedagogical dimensions can be used to articulate how flipped classrooms support these notions of student-centred learning.

Personalisation. Student-centeredness suggests flexibility and choice with learning activities and resources (Lea et al., 2003; Neumann, 2013). These ideas of student-centred learning are congruent with personalisation in flipped classrooms where lecturers use classroom time to support individual learning needs (Lage et al., 2000). Flipped classrooms also have potential to support learning personalisation through flexible learning environments that allow students to use different study modes, and to study at their preferred times and locations (Akçayır \& Akçayır, 2018; Brewer \& Movahedazarhouligh, 2018; Flipped Learning Network, 2014).

Higher-order thinking. The perspective of student-centred learning as involving deep and constructive learning (Howland et al., 2013; Lea et al., 2003) is evidenced in higher education flipped classrooms. Classroom time originally used for lectures is now focused on activities that foster students' higher-order or critical thinking (Akçayır \& Akçayır, 2018; Chen et al., 2017; Lage et al., 2000) through problem-solving and active knowledge application (e.g., Betihavas et al., 2016; Chen et al., 2017; Lin \& Hwang, 2018). Higher-order thinking also involves authentic and real-world knowledge construction (Hannafin et al., 1997; Howland et al., 2013) because students are often engaged in problem-solving with case studies or scenarios in higher education settings (Betihavas et al., 2016; O'Flaherty \& Phillips, 2015; Presti, 2016).

Self-direction. Student-centred learning supports student autonomy but in turn requires learners to undertake more responsibility for learning (Fay, 1988). These aspects of student-centred learning parallel what is described as self-direction of learning in higher education flipped classrooms where students are responsible for studying lecture content independently before class (Akçayır \& Akçayır, 2018; Betihavas et al., 2016). Such kinds of self-directed learning during flipped classrooms increases student intentionality towards study goals and learning processes (Brewer \& Movahedazarhouligh, 2018). Students also develop stronger perceptions of themselves as independent learners after experiencing learning in flipped classrooms (O'Flaherty \& Phillips, 2015).

Collaboration. As compared to teacher-centred environments, students have a larger stake in the learning processes of student-centred classrooms (Neumann, 2013). Collaboration through group work is one way of organising learning activities in flipped classrooms (Betihavas et al., 2016; Karabulut-Ilgu et al., 2018; Lage et al., 2000). This is because collaboration supports active learning (Karabulut-Ilgu et al., 2018) and provides students with opportunities to articulate their personal knowledge expressions within peerbased contexts (Akçayır \& Akçayır, 2018). Such kinds of social interaction in flipped classrooms enhances students' intrinsic motivation for learning by satisfying their needs for relatedness (Abeysekera \& Dawson, 2014).

Extant systematic reviews of flipped classrooms have explicated its supporting learning materials (e.g., instructional videos, animations, or e-books) and learning activities (e.g., problem-solving, quizzes, group work, discussion, social media, gaming, problem-based learning) (Akçayır \& Akçayır, 2018; Lin \& Hwang, 2018; Seery, 2015). These four dimensions can improve the pedagogical theorisation of flipped classrooms (Karabulut-Ilgu et al., 2018; O'Flaherty \& Phillips, 2015) through more precise definitions of the underlying pedagogical rationalisations to which its learning activities and materials are being applied. This can address the dearth of design guidance for lecturers that is observed in current studies (Lundin et al., 2018) and shed light about possible relationships between pedagogical design and student learning outcomes that not well-understood in blended learning studies (Bernard, Borokhovski, Schmid, Tamim, \& Abrami, 2014). 
This study therefore examines the following research questions: How do learning activities in flipped classrooms support the pedagogical dimensions of personalisation, higher-order problem solving, self-direction, and collaboration? What are their associated learning outcomes?

\section{Method}

\section{Selection of Studies and Search Terms}

This review examines actual practices of flipped or inverted learning in higher education published in both education and discipline-based education journals where learning outcomes have been documented. Referencing the reviews of flipped classrooms (e.g., Akçayır \& Akçayır, 2018; O'Flaherty \& Phillips, 2015), four databases indexing leading educational journals - Scopus, ProQuest (ERIC), Web of Science (Core Collection) for SSCI-listed journals, and EBSCO Education Complete were searched. The search terms used were "flipped classroom" or "inverted classroom" AND "higher education" AND "learning outcomes". As the aim of the study is to interpret current flipped classroom practices in light of the four pedagogical dimensions associated with student-centred learning, keywords related to the pedagogical dimensions were not included to avoid biasing the selection of studies towards those emphasising particular dimensions.

\section{Inclusion and Exclusion Criteria}

Study selection was based on the following criteria:

Time period. From year 2000 to 2018, as the term "flipped classrooms" was first proposed by Lage et al. (2000).

Type of article. Consistent with the quality practices in reviews of flipped classrooms (see Akçayır \& Akçayır, 2018; Karabulut-Ilgu et al., 2018; Lin \& Hwang, 2018; O'Flaherty \& Phillips, 2015), peerreviewed journal articles were selected for study. Non-refereed articles and conference proceedings were excluded.

Target audience. Undergraduate or graduates attending lessons conducted with inverted or flipped classrooms. Studies conducted in K-12 settings, pedagogical experiments conducted with recruited volunteers who were not registered course students as well as studies of lecturer professional development were excluded.

Description of pedagogy. To be included, the lessons described in each article must identify themselves as adopting flipped or inverted classrooms with activities clearly demarcated for pre-class and class sessions where students complete pre-class work in preparation for class sessions (Lin \& Hwang, 2018; Seery, 2015). Studies without clear description of the lesson content and activities for both pre-class and inclass learning were excluded. Studies evaluating only the effectiveness of technological systems used to support flipped classrooms were also excluded.

Research methodology. The sample size and research method should be clearly described for inclusion.

Learning outcomes. Drawing reference to the review of Akçayır and Akçayır (2018), flipped classroom learning outcomes in terms of assessments of knowledge, skills or attitudes should be reported. Studies reporting only student perceptions of learning experiences or anecdotal observations were excluded. Refereed articles that are opinion pieces, literature reviews, meta-studies, research briefs, and general flipped classroom surveys of students' or lecturers' perceptions were excluded but examined for background understanding. 
Database search was carried out from January to April 2019, during which the 763 references were also analysed by drawing reference to the PRISMA flow of information for systematic review (Moher, Liberati, Tetzlaff, Altman, \& Group, 2009). As per the PRISMA flow diagram, fifty-one articles were selected after removing duplicates and reviewing the titles, abstracts, and full articles with the selection criteria (See Figure 1).

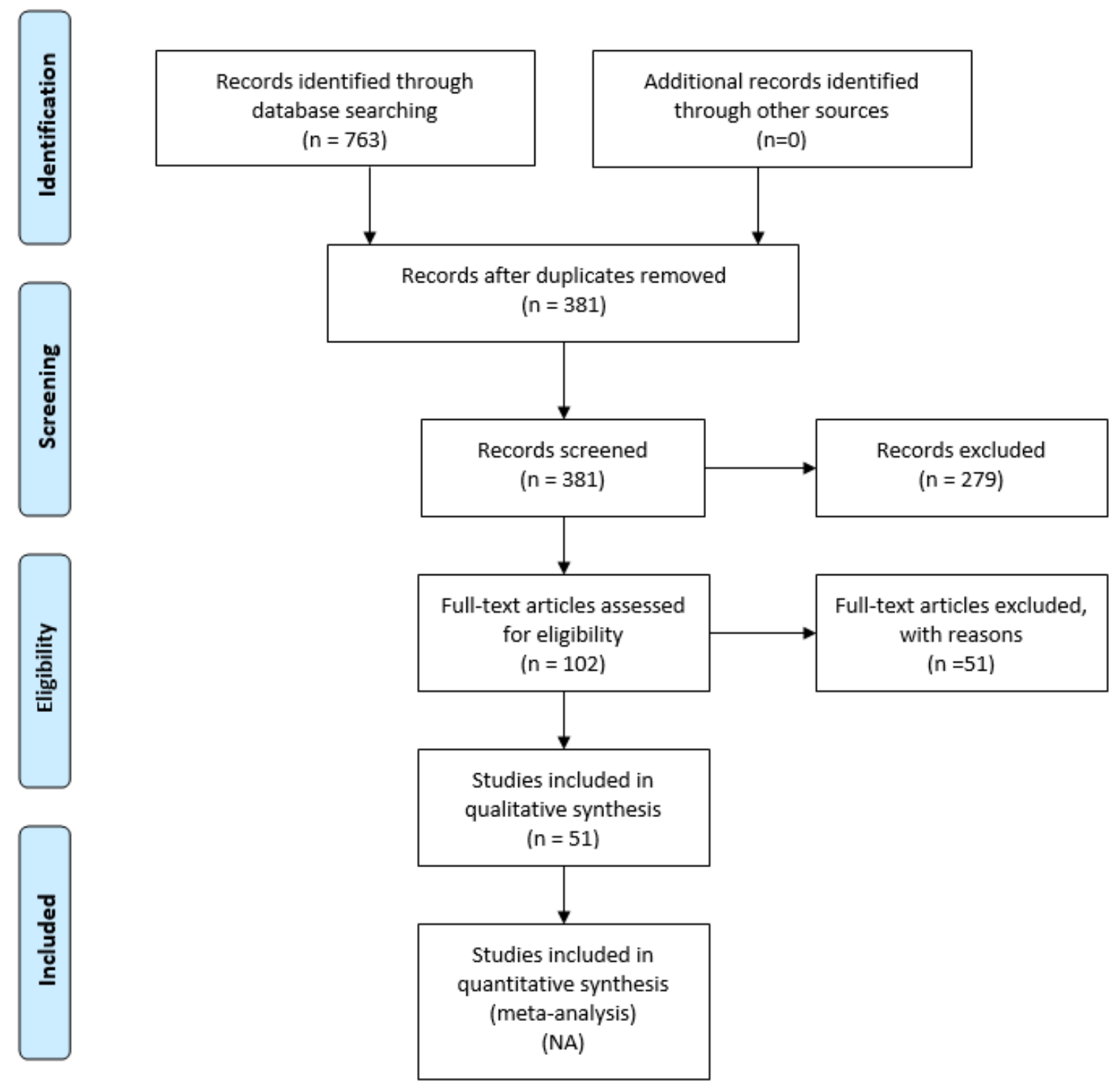

Figure 1. PRISMA flow diagram for selection of articles

From the 51 studies, 56 unique cases were eventually analysed as five studies examined varying flipped classroom designs (Butzler, 2016; Chis, Moldovan, Murphy, Pathak, \& Muntean, 2018; Foldnes, 2016; Hung, 2015; Lombardini, Lakkala, \& Muukkonen, 2018). Key information of the articles can be found in Appendix 1. 


\section{Data analysis}

The articles were first coded for their general characteristics of year, site of study, subject discipline, level of students, sample size, learning outcomes, and methodology to examine general research trends. Descriptions of lesson activities and learning outcomes were extracted for coding. Details of coding for each case is provided as additional information (see A1).

The research questions were examined through content analysis (Weber, 1990) of the descriptions of lesson activities and learning outcomes reported in each article. This coding and counting method were selected as it facilitated the inductive analysis of textual data into categories and the subsequent analysis of themes within and among categories. It also supported the identification of trends through the use of frequency counts as another dimension of data analysis.

Analysis of learning activities. Categories supporting each pedagogical dimension were first formulated with these guiding questions: Personalisation - How are individualized choices for learning supported?, Higher-order thinking - How is students' higher order thinking elicited?, Collaboration - How are learning collaborations among students supported?, Self-direction - How are students supported to take charge of learning?

Referencing the flipped classroom activities and practices that were articulated in reviews by Akçayır and Akçayır (2018), Lin and Hwang (2018), and Seery (2015), the lesson description of each article was analysed to distil the different learning activity categories used to support each pedagogical dimension. This process was repeated continually during which the activity categories were compared, re-labelled, removed, or combined by drawing upon the constant comparative method (Creswell, 1998) to ensure sufficient conceptual distinction among categories. This process was also applied within each pedagogical dimension to ensure conceptual fit among categories associated with the dimension. A second rater coded 15 randomly selected cases with the following Cohen's kappa: personalisation (0.88), higher order thinking (0.84), collaboration (0.87), and self-direction (0.81). The definitions of the categories and their coherence with the pedagogical dimensions were reviewed and refined through discussion to derive the finalised categories and frequency counts presented in the Findings section.

Analysis of learning outcomes. The definitions of Karabulut-Ilgu et al. (2018) were adapted to code the learning outcome of each case as follows: Positive - Flipped students had significantly better knowledge, skills or attitudinal outcomes; Mixed - Positive knowledge, skills or attitudinal outcomes of flipped students were not consistent; No significant differences - The knowledge, skills or attitudinal outcomes of flipped students were not significantly different from lecture-based students, or no significant pre-post study differences were reported; or Negative - Flipped students had significantly lower knowledge, skills or attitudinal outcomes. The trends of learning outcomes observed among the different learning activities associated with each pedagogical dimension were examined to answer the research question.

\section{Results}

\section{General Characteristics}

Time period. The 51 studies were published from 2013 to 2018 with $84.31 \%$ of the articles published after year 2016 (See Figure 2). The dearth of studies examining inverted learning prior to 2012 is consistent with recent reviews (Akçayır \& Akçayır, 2018; Karabulut-Ilgu et al., 2018). 


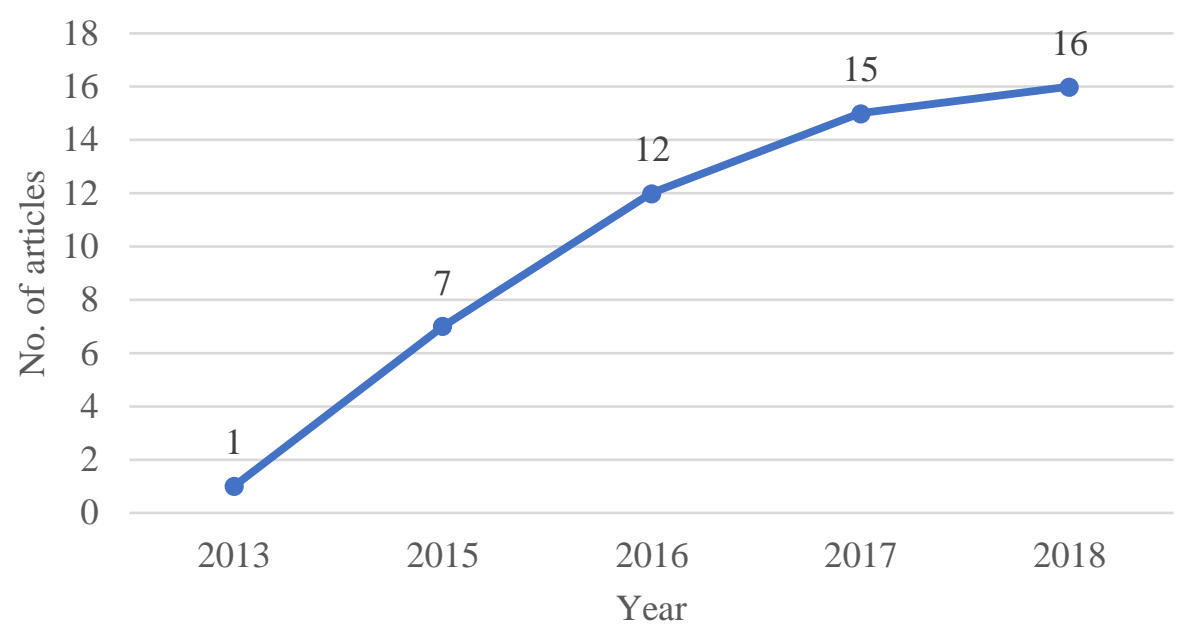

Figure 2. Publication trend

Site of study. More than half of the 51 studies were from North America $(n=26,50.98 \%)$ largely from the United States of America. The other studies were from Asia and Australasia $(n=12,23.53 \%)$, Middle East $(n=7,13.73 \%)$, and Europe $(n=6,11.76 \%)$.

Discipline. A wide range of disciplines was represented in the 51 studies with more than a quarter from Medicine, Dentistry, Health Sciences, and Nursing $(n=14,27.45 \%)$. Another 30\% was from Natural Sciences $(n=7,13.73 \%)$, and Education $(n=8,15.69 \%)$. Mathematics and Statistics $(n=7,13.73 \%)$ and Languages $(n=6,11.76 \%)$ constitute $25 \%$ of the studies. The rest were from Engineering and Computer Science $(n=4,7.84 \%)$, Business and Social Sciences $(n=5,9.80 \%)$.

Level of study. The 51 studies generally focused on undergraduate courses $(n=42,82.35 \%)$ and the remaining studies either examined graduate courses $(n=7,13.73 \%)$ or both undergraduate and graduate courses $(n=2,3.92 \%)$.

Study methodology. About $59 \%$ of the studies used quasi-experiments with intact comparison groups $(n=33,64.71 \%)$. Controlled experiments constituted about $20 \%$ of the studies $(n=11,21.57 \%)$ and the remaining studies used repeated measures $(n=6,11.76 \%)$ or correlational analysis $(n=1,1.96 \%)$.

Sample size. About $42 \%$ of the studies had sample sizes of less than $100(n=20,39.22 \%)$, about $30 \%$ of the studies had sample sizes between 100 to less than $200(n=16,31.37 \%)$. The rest of the studies had sample sizes of 200 and above $(n=15,29.41 \%)$.

Learning outcomes. Learning outcomes were examined with the 56 cases as some studies compared different flipped classroom designs. About $60 \%$ of the cases reported positive results $(N=33$, $58.93 \%$ ) where flipped classroom students had significantly better knowledge (e.g., test scores), skills performance, or measures of attitudinal outcomes (e.g., motivation) through repeated measures or when compared to lecture-based students. The rest of the studies reported mixed results $(N=9,16.07 \%)$, no significant differences $(N=13,23.21 \%)$, or negative results $(N=1,1.79 \%)$.

\section{Activities Underlying Pedagogical Dimensions and Their Learning Outcomes}

Personalisation. Table 1 shows that personalisation was supported through on-demand access to resources before class and on-demand access to teachers during class in all cases. 
Table 1. Personalisation support

\begin{tabular}{lcr}
\hline & $N$ & $\%$ \\
\hline Pre-class & & \\
On-demand resource access & 56 & 100.00 \\
$\quad$ Total & 56 & 100.00 \\
In class & 55 & 98.21 \\
$\quad$ On-demand teacher access & 1 & 1.79 \\
One-demand teacher access and choice of learning activity & 56 & 100.00 \\
$\quad$ Total & & \\
\hline
\end{tabular}

Pre-class. Learning is personalised as students have flexibility over when, where and how often they would like to access different online resources on-demand for pre-class preparation. Different kinds of online resources to support content transmission were used in all cases, including video lectures (e.g., Shiau et al., 2018), narrated PowerPoints (e.g., Dehghanzadeh \& Jafaraghaee, 2018), and content resources such as Youtube videos or readings (e.g., Gross, Pietri, Anderson, Moyano-Camihort, \& Graham, 2015). The use of cognitive tools such as visualisation apps (e.g., Eichler \& Peeples, 2016) which allowed students to simulate and manipulate content visualisations were rarely reported.

In-class. Personalisation during class occurs through on-demand access to the teacher for individual questions as students completed learning activities either individually or in groups (e.g., Butzler, 2016; Cakiroglu \& Ozturk, 2017). Despite having flexibility over the use of content resources, students were unable to choose learning activities nor resources outside those prescribed to them. Only one study (see Lombardini et al., 2018) personalised learning choice by allowing for optional group projects.

Learning outcomes. While the practice of personalisation during pre-class learning was generally uniform among the cases, the format of learning resources may influence student learning outcomes. Hung (2015) compared two flipped classrooms and found that students who used structured WebQuests for preclass learning had better exam performance than those using video lectures. In terms of in-class activities, the results of Lombardini et al. (2018) indicate the need to consider learning choice as a form of personalisation because flipped classroom students who were given choice for group work participation had better test scores than those who did not.

Higher-order thinking. The levels of application, analysis, synthesis, or creation specified by Bloom's taxonomy (Krathwohl, 2002) were commonly referenced as standards of higher-order thinking (e.g., Balaban, Gilleskie, \& Tran, 2016; Carter, Carter, \& Foss, 2018; Foldnes, 2016).

Table 2. Higher-order thinking activities

\begin{tabular}{lcr}
\hline & $N$ & $\%$ \\
\hline Pre-class & & \\
Application (e.g. homework \& quizzes) & 40 & 71.43 \\
Synthesis & 1 & 1.79 \\
No higher-order thinking activities reported & 15 & 26.78 \\
Total & 56 & 100.00 \\
In-class & & \\
Application (e.g. problem-solving, hands-on practice) & 23 & 41.07 \\
Analysis (Complex problem-solving \& case discussions) & 29 & 51.79 \\
Creation (Design products or practices) & 4 & 7.14 \\
Total & 56 & 100.00 \\
\hline
\end{tabular}


Pre-class. Table 2 shows that the application level was supported in about $71 \%$ of the pre-class activities through assigned homework and quizzes (e.g., Baytiyeh \& Naja, 2017). The synthesis level of Bloom's taxonomy was only observed in White et al. (2017) who required students to prepare concept maps articulating their summaries of lecture content before attending class. Activities for students to apply higherorder thinking were not reported in the rest of the cases where students were largely expected to review the content resources provided to them before coming to class (e.g., Burgoyne \& Eaton, 2018).

In-class. Majority of the cases supported higher order thinking during class through application and analysis. Application of knowledge involved solving homework problems (e.g., Tune, Sturek, \& Basile, 2013), language practice exercises (e.g., Lin \& Hwang, 2018) or computer programming exercises (e.g., Chis et al., 2018) whereas analysis involved complex problem-solving in subject areas such as mathematics (e.g., Yong, Levy, \& Lape, 2015) or case discussions in professional disciplines such as dentistry (e.g., Lee \& Kim, 2018). The highest Bloom's level of creation was only observed in four cases where students designed actual products or practices. In Kurt (2017) for example, education students designed and tested the efficacy of their classroom management strategies through role-plays.

Learning outcomes. About 59\% $(n=24)$ of the cases that prescribed students with application or synthesis-type activities before class reported positive learning outcomes (e.g., Anderson et al., 2017) and this was comparable to 60\% ( $n=9)$ among the cases that did not (e.g., Lee \& Kim, 2018).

Different trends in learning outcomes were observed among in-class activities. About $69 \%(n=20)$ of the cases that used analysis-type activities during class reported positive learning outcomes such as significant improvement in pre and post-study test scores (Chen \& Chang, 2017) as well as flipped classroom students having significantly better test or exam scores (e.g., Cotta, Shah, Almgren, MacíasMoriarity, \& Mody, 2016; Dehghanzadeh \& Jafaraghaee, 2018; Eichler \& Peeples, 2016), self-regulated learning practices (Cakiroglu \& Ozturk, 2017), and critical thinking (Dehghanzadeh \& Jafaraghaee, 2018) than lecture-based students. All the four cases that implemented creation-type activities during class reported flipped classroom students achieving significantly better performance in tests, exams, or skills than those experiencing traditional lectures (Chis et al., 2018; Elmaadaway, 2018; Kurt, 2017), or were able to transfer and exhibit higher levels of graphic design skills from their group to individual projects $(\mathrm{Ng}, 2018)$.

The trends of positive learning outcomes were not as evident among the cases using applicationtype activities during class. Only 39\% $(n=9)$ of these cases reported flipped classroom students having significantly better test or exam scores than lecture-based students (e.g., Asiksoy \& Ozdamli, 2016; Balaban et al., 2016). Close to a third of these cases $(n=7)$ reported no significant differences, especially when class sessions were used for individual homework practice and one-to-one consultation with minimal structured activities (Butzler, 2016; Chis et al., 2018; Foldnes, 2016). The results of Goates, Nelson, and Frost (2017) also show the need to consider lesson content when designing application-type activities. When learning literature search skills, flipped classroom students who viewed lecture videos before class performed worse in database search tasks during class as compared to lecture-based students who performed database search tasks right after the in-class lecture.

\section{Collaboration}

Pre-class. Collaboration was rarely reported during pre-class activities (See Table 3). When flipped classroom students had to view video lectures and do groupwork before class, they reported more study burden than lecture-based students even though they agreed that flipped classrooms improved their communication and clinical reasoning skills (Tang et al., 2017). 
Table 3. Collaboration support

\begin{tabular}{lcr}
\hline & $N$ & $\%$ \\
\hline Pre-class & & \\
Peer group & 5 & 8.93 \\
No collaboration reported & 51 & 91.07 \\
Total & 56 & 100.00 \\
In-class & & \\
Peer group & 42 & 75.00 \\
Design group & 3 & 5.36 \\
No collaboration reported & 11 & 19.64 \\
Total & 56 & 100.00 \\
\hline
\end{tabular}

In-class. Collaboration was reported in about $80 \%$ of the cases through either peer or design groups during class. Peer groups solved worksheet problems or discussed cases together during class with no further collaboration thereafter (e.g., Eichler \& Peeples, 2016). Design groups created and tested the effectiveness of artefacts or solutions, sometimes across a period of time. In Chis et al. (2018) for example, students worked in groups to design a software application across three weeks of the semester.

Despite the widespread use of collaborative learning during class, there were only sporadic reports of non-random strategies for group organisation such as having intact groups throughout the semester to enhance group collegiality (e.g., Gross et al., 2015), or forming groups using students' academic profiles to enhance their learning interactions (e.g., Cakiroglu \& Ozturk, 2017). Details about the collaborative processes employed among cases tend to be sparse except for the five cases adopting the team-based learning approach developed by Michaelsen and Sweet (2011) that involved structured processes for individual practice and group practice (see Anderson et al., 2017; Boeve et al., 2017; Foldnes, 2016; Gross et al., 2015; Muzyk et al., 2015).

Learning outcomes. All the cases that assigned pre-class collaboration work reported positive learning outcomes (Cakiroglu \& Ozturk, 2017; Tang et al., 2017; White et al., 2017; Wu, Jun, \& Yang, 2017; Zeng et al., 2017) as compared to only about 55\% $(n=28)$ among the cases that did not.

Some form of collaboration during class appeared to support positive learning outcomes. Two studies examining different cases of flipped classroom designs found test performance to be significantly higher when learning through design groups and peer groups rather than through individual problem practice in class (Chis et al., 2018; Foldnes, 2016). Furthermore, 62\% $(n=28)$ of the cases that supported student collaboration during class through peer or design groups reported positive student learning outcomes (e.g., Koo et al., 2016; Kurt, 2017) as compared to 45\% $(n=5)$ among the cases that did not (e.g., Cotta et al., 2016; Thai, De Wever, \& Valcke, 2017). However, the mere use of collaborative learning may not necessarily result in positive learning outcomes when flipped classroom students were compared against students who attended lectures with active learning components (see Jensen, Kummer, \& Godoy, 2015; Lee \& Wallace, 2018; Lombardini et al., 2018; Ryan \& Reid, 2016; Saterbak, Volz, \& Wettergreen, 2016; Shiau et al., 2018). For example, in Jensen et al., students in the lecture condition had opportunities to explore biological phenomenon in groups. On the other hand, some form of structured processes for collaboration may better support positive learning outcomes. Except for Muzyk et al., who found no significant flippedlecture differences, all the cases that used team-based learning to support flipped classrooms reported better test scores for their flipped classes (Anderson et al., 2017; Boeve et al., 2017; Foldnes, 2016; Gross et al., 2015). 


\section{Self-direction}

Pre-class. About three-quarters of the cases provided students with resources such as quizzes (e.g., Ryan \& Reid, 2016) and answer keys (e.g., Asiksoy \& Ozdamli, 2016) for self-assessment as part of their pre-class preparation, or some form of study support such as note-taking templates (Butzler, 2016) or instructions for students to document their areas of doubt (e.g., Cronhjort, Filipsson, \& Weurlander, 2018) (See Table 4). Instructor or peer feedback for pre-class work (e.g., Wu et al., 2017) were rarely reported. Furthermore, no particular support for student self-direction was reported in about $20 \%$ of the cases.

Table 4. Self-direction support

\begin{tabular}{lrr}
\hline & $N$ & $\%$ \\
\hline Pre-class & & \\
Self-assessment resources (e.g., quiz, answer keys) or study support (e.g., note-taking & 43 \\
templates, documenting queries) & 2 & 76.7 \\
Teacher or peer feedback & 11 \\
No self-direction support reported & 56 \\
Total & 41 & 100.64 \\
In-class & 41 \\
Teacher review & 14 \\
Repeated application and remediation & 1 & 73.22 \\
Metacognitive review & 56.62 \\
Total & 1.79 \\
& 100.00 \\
\hline
\end{tabular}

In-class. Teacher review was a preponderant way of supporting student self-direction where teachers informed students about their learning gaps by providing feedback during class discussions (e.g., Thai et al., 2017), giving mini-lectures to remediate problem areas that they observed from students' preclass work (e.g., Wozny, Balser, \& Ives, 2018), or using quizzes at either at the beginning or end of class sessions to check and remediate students' problem areas (e.g., Olitsky \& Cosgrove, 2016).

About a quarter of the cases encouraged students to be more actively engaged in articulating and assessing their personal learning gaps through structured activities to support repeated application and remediation. For example, in Entezari and Javdan (2016), students solved problems in groups, did individual quizzes to check their understanding and also reflected on their learning gaps whereas in Chen and Chang (2017), students refined their ideas of educational practices through multiple presentation, feedback, and improvement cycles. The team-based learning process also supported repeated application and remediation because students first did an individual readiness test (IRAT) prior to discussing with their peer group to formulate a group answer to the readiness assurance test (RAT). These answers were then presented and clarified by the lecturer before the group worked on higher- order problems (Michaelsen \& Sweet, 2011).

While the cases that used repeated application and remediation focused on performance review, one case demonstrated support for the metacognitive aspect of self-direction where students were given opportunities to solve complex problems, rate the quality of solutions submitted by the class, and then examine their own problem-solving strategies (see White et al., 2017). Such kinds of activities allow students to be more deeply involved in confronting their thinking and problem-solving strategies but were not commonly used for self-direction support among the cases analysed.

Learning outcomes. Supporting pre-class preparation with self-assessment resources or feedback appeared to be efficacious for student learning outcomes. About $62 \%(n=28)$ of the cases that provided such kinds of support reported positive student learning outcomes (e.g., Elmaadaway, 2018) as compared 
to about $45 \%(n=5)$ among those that did not (Gross et al., 2015). Positive learning outcomes appeared more consistent among cases that supported students to engage in continual performance review through repeated opportunities for application and remediation. About $86 \%(n=12)$ of these cases reported positive student learning outcomes. Notably, several cases made comparisons with control groups who experienced active learning during lectures (Eichler \& Peeples, 2016; Fautch, 2015; Lee \& Wallace, 2018; Lombardini et al., 2018; Nielson, Bean, \& Larsen, 2018; White et al., 2017).

Student engagement in metacognitive review also appeared to be beneficial for complex problemsolving as White et al. (2017) reported flipped classroom students having better examination performance for questions requiring novel scenario analysis than lecture-based students. Teacher review of student learning gaps did not appear as successful because only $49 \%(n=20)$ of the cases using this self-direction strategy reported positive learning outcomes (e.g., Tangiisuran, Tye, \& Tan, 2017).

\section{Discussion}

This review found that flipped classrooms have been applied across higher education institutions in different geographic regions and disciplines. Content analysis of 56 cases found that different kinds of flipped classroom activities can be used to support student-centred learning through personalisation, higherorder thinking, collaboration, and self-direction. Personalisation occurs through on-demand resource access before class and on-demand teacher access during class. Pre-class activities that foster basic understanding and application are developed into higher-order thinking through in-class activities that emphasise complex application, analysis, and creation whereas individual learning is further deepened through collaboration in both peer and design groups during class. Besides teacher review of their learning gaps, student selfdirection is also supported through structured processes for repeated application and remediation as well as metacognitive review during class. It should be noted that these observations of flipped classroom practices were derived from the lesson descriptions of the selected studies and the heterogeneity of study aims may have resulted in researchers emphasising particular aspects of their lesson implementation. The use of learning outcomes as an inclusion criterion may have also resulted in the dominance of studies that are controlled or quasi experiments. Within these limitations, the various learning practices derived demonstrate examples of how pedagogical coherence can be established between the pre-class and in-class activities of flipped classrooms (O'Flaherty \& Phillips, 2015; Seery, 2015). These practices have generally resulted in positive student learning outcomes and can be subjected to further empirical validation.

\section{Practice Gaps and Areas of Future Research}

Several practice gaps that surfaced through the study point to areas of future research.

Self-direction support during pre-class learning. Self-direction involves students setting learning goals, planning, evaluating, and refining their learning strategies (Pilling-Cormick \& Garrison, 2007). Competencies for self-direction cannot be assumed as uniform among students (Long, Cummins, \& Waugh, 2017) because learning analytics studies show that high performing students tend to maintain frequent access to online materials (AlJarrah, Thomas, \& Shehab, 2018), execute metacognitive strategies during pre-course learning (Yilmaz, 2017) and adapt their learning strategies according to course requirements throughout the semester (Jovanovic et al., 2017). The level of students' pre-class preparation influences their learning outcomes in flipped classrooms (Gross et al., 2015) but self-direction support and feedback are generally not reported in the studies reviewed (see Table 4). These findings reveal the need for more research on student learning analytics of pre-class study behaviours, especially the differences between 
students with stronger and weaker learning performance. This can provide critical insights for planning selfdirection support strategies for pre-class learning according to student needs.

Personalisation of learning choices. The findings suggest that students experience personalisation through access to resources and teachers but have limited personalisation in terms of their learning choices. Neumann (2013) emphasises that student-centred learning involves academic choice. Student autonomy enhances their preferences for and perceived effectiveness of flipped classrooms (Masland \& Gizdarska, 2018; Uskoković, 2018). The future development of flipped classrooms should consider different ways of personalising learning choice as well as the learning and motivational outcomes on students. However, it is noted that autonomy with learning choice needs to be considered in tandem with students' propensity for self-direction (Howitt \& Pegrum, 2015). The study reveals that support for students' metacognitive selfdirection, especially in the area of performance monitoring and learning strategy improvement (PillingCormick \& Garrison, 2007) to be lacking. Future research should articulate how metacognitive selfdirection could be better used to facilitate students' effective appropriation of learning choices.

Structured collaboration processes. Group work appears to be a predominant learning strategy used in the studies reviewed but apart from team-based learning, there is generally a dearth of collaborative frameworks used in flipped classrooms. Structured group processes are needed to facilitate learning interactions as students do not naturally transition from social to academic relationships with their groups in flipped classrooms (McCollum, Fleming, Plotnikoff, \& Skagen, 2017). Moreover, during flipped learning, students who perceive good contribution from group members tend to value group work and learn effectively during flipped learning (Huang \& Lin, 2017). This could also explain why the study results show that team-based learning generally enhances learning effectiveness (e.g., Anderson et al., 2017). The design and engagement of collaborative processes beyond team-based learning can enhance the plethora of collaborative strategies used in flipped classrooms. Comparison studies explicating the learning and motivation outcomes of different collaborative strategies used to support flipped classrooms is another area of future research.

Students' workload perceptions. Flipped classroom students perceived that they committed more pre-class study time than lecture-based students (Burgoyne \& Eaton, 2018; Cakiroglu \& Ozturk, 2017; Jensen et al., 2015; Zeng et al., 2017). There is negative affect when students perceive that positive learning outcomes did not commensurate with their workload (e.g., Tang et al., 2017). Yet, it is found that student workload perceptions are complex. It is influenced by their willingness to engage in flipped classroom activities, which is in turn influenced by their motivation for learning, e-learning readiness, and preferences for flexibility and independent learning (Fraga \& Harmon, 2014; Yilmaz, 2017). Consideration of students' workload perceptions did not feature prominently within the description of flipped classroom activities examined. The intramental influences of student workload perceptions, how these affect student learning outcomes, as well as how the pedagogical dimensions can be better engaged in light of these perceptions is an area for further research.

Beyond content transmission technologies. This study shows that online technologies are largely used to support content transmission for pre-class learning. However, there is evidence that online materials facilitating structured inquiry can result in better learning outcomes than video lectures (Hung, 2015) but, as in this study, the use of technology tools for cognitive meaning making are rarely reported (Lin \& Hwang, 2018). Studies of emerging technologies supporting gamification, learning analytics, and self-regulation of resource access suggest that such technological affordances can enhance flipped classroom outcomes (Munoz-Merino et al., 2017; Shyr \& Chen, 2018). Mobile technologies and social media tools can also extend learning interactions from classrooms to online learning communities (e.g., Wu et al., 2017) but their 
use has rarely been reported. The enactment of the pedagogical dimensions through emerging technologies needs to be further considered as this can expand students' choice of learning modes in flipped classrooms.

Pedagogical dimensions and learning outcomes. There is some evidence from this study that flipped classroom students who learnt in peer groups, engaged in analysis and creation-type activities, and had self-direction support through repeated application and remediation had better test performance than those who did individual learning during class (e.g., Foldnes, 2016; Lombardini, et al., 2018). There are also studies that report no significant differences in test scores between flipped classroom students who learnt in peer groups and those who attended lectures with active learning components (Jensen et al., 2015; Lee \& Wallace, 2018; Lombardini et al., 2018; Ryan \& Reid, 2016; Saterbak et al., 2016; Shiau et al., 2018). These results suggest that the dimensions can be used as theoretical vocabulary to derive insights about the pedagogical aspects of flipped classrooms that drive learning outcomes. However, the heterogeneity of research aims among the selected studies implies that these findings should only be considered as indicative. While this study has selected peer-reviewed articles from leading journals as a way of ensuring review quality (Akçayır \& Akçayır, 2018), it is unable to account for the potential of publication bias through preferred acceptance of studies reporting positive findings during peer-review (Hopewell, Loudon, Clarke, Oxman, \& Dickersin, 2009; Stern \& Simes, 1997). Furthermore, the dominance of experimental studies analysed suggest that the flipped classroom practices and outcomes observed still need to be further understood from a qualitative perspective. These study limitations suggest the need for further empirical verification of the relationships observed between the pedagogical dimensions and learning outcomes both qualitatively and quantitatively.

\section{Conclusion}

This study suggests that flipped classrooms can be used to support student-centred learning through the pedagogical dimensions of personalisation, higher-order thinking, collaboration, and self-direction. These dimensions can be used to improve the theorisation of flipped classroom practices, aid lecturer design of flipped classrooms, and also reveal its practice gaps. By using these dimensions as a common theoretical vocabulary for the development and comparison of flipped classroom designs, the relationships between the pedagogical design and student learning outcomes of flipped classrooms can be pinpointed more clearly than general flipped-lecture comparisons. This approach can be used for the continual improvement of flipped classroom practices.

\section{References}

\section{References marked with an asterisk indicate studies included in this systematic review}

Abeysekera, L., \& Dawson, P. (2014). Motivation and cognitive load in the flipped classroom: definition, rationale and a call for research. Higher Education Research \& Development, 34, 1 - 14. doi: 10.1080/07294360.2014. 934336

Akçayır, G., \& Akçayır, M. (2018). The flipped classroom: A review of its advantages and challenges. Computers \& Education, 126, 334 - 345. https://doi.org/10.1016/j.compedu.2018.07.021

Alexander, P. A., \& Murphy, P. K. (1998). The research base for APA's learner-centered psychological principles. In How students learn: Reforming schools through learner-centered education (pp. 25-60). Washington, D.C.: American Psychological Association.

AlJarrah, A., Thomas, M. K., \& Shehab, M. (2018). Investigating temporal access in a flipped classroom: procrastination persists. International Journal of Educational Technology in Higher Education, 15, 1 - 18. doi: 10.1186/s41239-017-0083-9 
*Anderson, H. G., Frazier, L., Anderson, S. L., Stanton, R., Gillette, C., Broedel-Zaugg, K., \& Yingling, K. (2017). Comparison of pharmaceutical calculations learning outcomes achieved within a traditional lecture or flipped classroom andragogy. American Journal of Pharmaceutical Education, 81, 1 - 9. doi: 10.5688/ajpe81470

*Asiksoy, G., \& Ozdamli, F. (2016). Flipped Classroom adapted to the ARCS Model of Motivation and applied to a Physics Course. Eurasia Journal of Mathematics Science and Technology Education, 12, 1589 - 1603. doi: 10.12973/eurasia.2016.1251a

*Balaban, R. A., Gilleskie, D. B., \& Tran, U. (2016). A quantitative evaluation of the flipped classroom in a large lecture principles of economics course. Journal of Economic Education, 47, 269 - 287. doi:10.1080/00220485.2016. 1213679

*Baytiyeh, H., \& Naja, M. K. (2017). Students' perceptions of the flipped classroom model in an engineering course: a case study. European Journal of Engineering Education, 42, 1048 - 1061. doi: 10.1080/03043797.2016.12 52905

Bergmann, J., \& Sams, A. (2012). Flip your classroom: reach every student in every class every day (1st ed.). Alexandria, VA: International Society for Technology in Education.

Bernard, R., Borokhovski, E., Schmid, R., Tamim, R., \& Abrami, P. (2014). A meta-analysis of blended learning and technology use in higher education: from the general to the applied. Journal of Computing in Higher Education, 26, 87 - 122. doi: 10.1007/s12528-013-9077-3

Betihavas, V., Bridgman, H., Kornhaber, R., \& Cross, M. (2016). The evidence for 'flipping out': a systematic review of the flipped classroom in nursing education. Nurse Education Today, 38, 15 - 21. doi: 10.1016/j.nedt.2015. 12.010

*Boeve, A. J., Meijer, R. R., Bosker, R. J., Vugteveen, J., Hoekstra, R., \& Albers, C. J. (2017). Implementing the flipped classroom: an exploration of study behaviour and student performance. Higher Education, 74, 1015 1032. doi: 10.1007/s10734-016-0104-y

Brewer, R., \& Movahedazarhouligh, S. (2018). Successful stories and conflicts: A literature review on the effectiveness of flipped learning in higher education. Journal of Computer Assisted Learning, 34, 409 - 416. https://doi.org/10.1111/jcal.12250

*Burgoyne, S., \& Eaton, J. (2018). The partially flipped classroom: The effects of flipping a module on "Junk Science" in a large methods course. Teaching of Psychology, 45, 154 - 157. doi: 10.1177/0098628318762894

*Butzler, K. B. (2016). The synergistic effects of self-regulation tools and the flipped classroom. Computers in the Schools, 33, 11 - 23. http://dx.doi.org/10.1080/07380569.2016.1137179

*Cakiroglu, U., \& Ozturk, M. (2017). Flipped classroom with problem-based activities: Exploring self-regulated learning in a Programming Language course. Educational Technology \& Society, 20, 337 - 349.

Cannon, R., \& Newbie, D. (2000). A guide to improving teaching methods: A handbook for teachers in university and colleges. UK: Kogan Page.

*Carter, C. L., Carter, R. L., \& Foss, A. H. (2018). The flipped classroom in a terminal college mathematics course for liberal arts students. AERA Open, 4, 1 - 14. https://doi.org/10.1177/2332858418759266

Chen, F., Lui, A. M., \& Martinelli, S. M. (2017). A systematic review of the effectiveness of flipped classrooms in medical education. Medical Education, 51, 585 - 597. https://doi.org/10.1111/medu.13272

*Chen, H. L., \& Chang, C. Y. (2017). Integrating the SOP${ }^{2}$ model into the flipped classroom to foster cognitive presence and learning achievements. Educational Technology \& Society, 20, 274 - 291.

*Chis, A. E., Moldovan, A. N., Murphy, L., Pathak, P., \& Muntean, C. H. (2018). Investigating flipped classroom and problem-based learning in a programming module for computing conversion course. Educational Technology \& Society, 21, $232-247$.

*Cotta, K. I., Shah, S., Almgren, M. M., Macías-Moriarity, L. Z., \& Mody, V. (2016). Effectiveness of flipped classroom instructional model in teaching pharmaceutical calculations. Currents in Pharmacy Teaching \& Learning, 8, 646 - 653. doi: 10.1016/j.cptl.2016.06.011

Creswell, J. W. (1998). Qualitative inquiry and research design. Thousand Oaks, CA: SAGE Publications.

*Cronhjort, M., Filipsson, L., \& Weurlander, M. (2018). Improved engagement and learning in flipped-classroom calculus. Teaching Mathematics \& its Applications, 37, 113 - 121. doi: 10.1093/teamat/hrx007

*Dehghanzadeh, S., \& Jafaraghaee, F. (2018). Comparing the effects of traditional lecture and flipped classroom on nursing students' critical thinking disposition: A quasi-experimental study. Nurse Education Today, 71, 151 156. doi: 10.1016/j.nedt.2018.09.027

*Eichler, J. F., \& Peeples, J. (2016). Flipped classroom modules for large enrollment general chemistry courses: a low barrier approach to increase active learning and improve student grades. Chemistry Education Research and Practice, 17, 197 - 208. doi: 10.1039/C5RP00159E 
*Elmaadaway, M. A. N. (2018). The effects of a flipped classroom approach on class engagement and skill performance in a Blackboard course. British Journal of Educational Technology, 49, 479 - 491. doi: $10.1111 /$ bjet. 12553

*Entezari, M., \& Javdan, M. (2016). Active learning and flipped classroom, hand in hand approach to improve students learning in Human Anatomy and Physiology. International Journal of Higher Education, 5, 222 - 231.

*Fautch, J. M. (2015). The flipped classroom for teaching organic chemistry in small classes: Is it effective? Chemistry Education Research and Practice, 16, 179 - 186. doi: 10.1039/c4rp00230j

Fay, P. (1988). Open and student-centred learning: Evangelism and heresy. Journal of Further and Higher Education, 12, 3 - 19. doi: 10.1080/0309877880120101

Flipped Learning Network. (2014). Definition of flipped learning. Retrieved from https:/flippedlearning.org/ definition-of-flipped-learning/

*Foldnes, N. (2016). The flipped classroom and cooperative learning: Evidence from a randomised experiment. Active Learning in Higher Education, 17, 39 - 49. doi: 10.1177/1469787415616726

Fraga, L. M., \& Harmon, J. (2014). The Flipped Classroom Model of Learning in Higher Education: An Investigation of Preservice Teachers' Perspectives and Achievement. Journal of Digital Learning in Teacher Education, 31, 18 - 27. http://dx.doi.org/10.1080/21532974.2014.967420

*Goates, M. C., Nelson, G. M., \& Frost, M. (2017). Search strategy development in a flipped library classroom: A student-focused assessment. College \& Research Libraries, 78, 382 - 395. doi: 10.5860/crl.78.3.382

Grajek, S. (2016). Trend Watch 2016: Which IT trends Is higher education responding to? Retrieved from https://library.educause.edu/ /media/files/library/2016/3/ers1601tr.pdf

*Gross, D., Pietri, E. S., Anderson, G., Moyano-Camihort, K., \& Graham, M. J. (2015). Increased preclass preparation underlies student outcome improvement in the flipped classroom. CBE-Life Sciences Education, 14, 1 - 8. doi: 10.1187/cbe.15-02-0040

Hannafin, M. J., Hill, J. R., \& Land, S. M. (1997). Student-centered learning and interactive multimedia: Status, issues, and implication. Contemporary Education, 68, 94 - 99.

Hopewell, S., Loudon, K., Clarke, M. J., Oxman, A. D., \& Dickersin, K. (2009). Publication bias in clinical trials due to statistical significance or direction of trial results. Cochrane Database of Systematic Reviews (1). doi: 10.1002/14651858.MR000006.pub3

Howitt, C., \& Pegrum, M. (2015). Implementing a flipped classroom approach in postgraduate education: An unexpected journey into pedagogical redesign. Australasian Journal of Educational Technology, 31, 458 469. doi: 10.14742/ajet.2439

Howland, J. L., Jonassen, D., \& Marra, R. M. (2013). Meaningful learning with technology (4th ed.). New York: Pearson Higher Education.

Huang, C. K., \& Lin, C. Y. (2017). Flipping business education: Transformative use of team-based learning in human resource management classrooms. Educational Technology \& Society, 20, 323 - 336.

*Hung, H. T. (2015). Flipping the classroom for English language learners to foster active learning. Computer Assisted Language Learning, 28, 81 - 96. doi: 10.1080/09588221.2014.967701

*Jensen, J. L., Kummer, T. A., \& Godoy, P. (2015). Improvements from a flipped classroom may simply be the fruits of active learning. Cbe-Life Sciences Education, 14, 1 - 12. doi: 10.1187/cbe.14-08-0129

Karabulut-Ilgu, A., Jaramillo Cherrez, N., \& Jahren, C. T. (2018). A systematic review of research on the flipped learning method in engineering education. British Journal of Educational Technology, 49, 398 - 411. https://doi.org/10.1111/bjet.12548

Kember, D., \& Wong, A. (2000). Implications for evaluation from a study of students' perceptions of good and poor teaching. Higher Education, 40, 69 - 97. http://dx.doi.org/10.1023/A:1004068500314

*Koo, C. L., Demps, E. L., Farris, C., Bowman, J. D., Panahi, L., \& Boyle, P. (2016). Impact of flipped classroom design on student performance and perceptions in a Pharmacotherapy course. American Journal of Pharmaceutical Education, 80, 1 - 9. doi: 10.5688/ajpe80233

Krathwohl, D. R. (2002). A revision of Bloom's taxonomy: An overview. Theory into Practice, 41, 212 - 218.

*Kurt, G. (2017). Implementing the flipped classroom in teacher education: Evidence from Turkey. Journal of Educational Technology \& Society, 20, 211 - 221.

Lage, M. J., Platt, G. J., \& Treglia, M. (2000). Inverting the classroom: A gateway to creating an inclusive learning environment. The Journal of Economic Education, 31, 30 - 43.

Lea, S. J., Stephenson, D., \& Troy, J. (2003). Higher Education Students' Attitudes to Student-centred Learning: Beyond 'educational bulimia'? Studies in Higher Education, 28, 321 - 334. doi: 10.1080/03075070309293

*Lee, C., \& Kim, S. W. (2018). Effectiveness of a flipped classroom in learning periodontal diagnosis and treatment planning. Journal of Dental Education, 82, 614 - 620. doi: 10.21815/jde.018.070 
*Lee, G., \& Wallace, A. (2018). Flipped learning in the English as a foreign language classroom: Outcomes and perceptions. Tesol Quarterly, 52, 62 - 84. doi: 10.1002/tesq.372

*Lin, C. J., \& Hwang, G. J. (2018). A learning analytics approach to investigating factors affecting EFL students' oral performance in a flipped classroom. Journal of Educational Technology \& Society, 21, 205 - 219.

Lin, H. C., \& Hwang, G. J. (2018). Research trends of flipped classroom studies for medical courses: A review of journal publications from 2008 to 2017 based on the technology-enhanced learning model. Interactive Learning Environments, 1 - 17. https://doi.org/10.1080/10494820.2018.1467462

*Lombardini, C., Lakkala, M., \& Muukkonen, H. (2018). The impact of the flipped classroom in a principles of microeconomics course: evidence from a quasi-experiment with two flipped classroom designs. International Review of Economics Education, 29, 14 - 28. doi: 10.1016/j.iree.2018.01.003

Long, T., Cummins, J., \& Waugh, M. (2017). Use of the flipped classroom instructional model in higher education: instructors' perspectives. Journal of Computing in Higher Education, 29, 179 - 200. doi: 10.1007/s12528016-9119-8

Lundin, M., Bergviken Rensfeldt, A., Hillman, T., Lantz-Andersson, A., \& Peterson, L. (2018). Higher education dominance and siloed knowledge: a systematic review of flipped classroom research. International Journal of Educational Technology in Higher Education, 15, 1 - 1. doi: 10.1186/s41239-018-0101-6

Masland, L., \& Gizdarska, S. (2018). "Then what am I paying you for?" Student attitudes regarding pre-class activities for the flipped classroom. International Journal of Teaching and Learning in Higher Education, 30, 234 244.

McCollum, B. M., Fleming, C. L., Plotnikoff, K. M., \& Skagen, D. N. (2017). Relationships in the flipped classroom. Canadian Journal for the Scholarship of Teaching and Learning, 8, 1 - 21. https://doi.org/10.5206/cjsotlrcacea.2017.3.8

Michaelsen, L. K., \& Sweet, M. (2011). Team-based learning. New directions for teaching and learning, 2011,41 51. https://doi.org/10.1002/tl.467

Moher, D., Liberati, A., Tetzlaff, J., Altman, D. G., \& Group, P. (2009). Preferred reporting items for systematic reviews and meta-analyses: the PRISMA statement. Annals of Internal Medicine, 151, 264 - 269. https://doi.org/10.1371/journal.pmed.1000097

Munoz-Merino, P. J., Ruiperez-Valiente, J. A., Kloos, C. D., Auger, M. A., Briz, S., de Castro, V., \& Santalla, S. N. (2017). Flipping the classroom to improve learning with MOOCs technology. Computer Applications in Engineering Education, 25, 15 - 25. doi: 10.1002/cae.21774

*Muzyk, A. J., Fuller, S., Jiroutek, M. R., Grochowski, C. O., Butler, A. C., \& Byron May, D. (2015). Implementation of a flipped classroom model to teach psychopharmacotherapy to third year Doctor of Pharmacy (PharmD) students. Pharmacy Education, 15, 44 - 53.

Neumann, J. W. (2013). Developing a new framework for conceptualizing "Student-Centered Learning". The Educational Forum, 77, 161 - 175. doi: 10.1080/00131725.2012.761313

*Ng, E. M. W. (2018). Integrating self-regulation principles with flipped classroom pedagogy for first year university students. Computers \& Education, 126, 65 - 74. doi: 10.1016/j.compedu.2018.07.002

*Nielson, P. L., Bean, N. W. B., \& Larsen, R. A. A. (2018). The impact of a flipped classroom model of learning on a large undergraduate Statistics class. Statistics Education Research Journal, 17, 121 - 140.

O'Flaherty, J., \& Phillips, C. (2015). The use of flipped classrooms in higher education: A scoping review. The internet and higher education, 25, 85 - 95. https://doi.org/10.1016/j.iheduc.2015.02.002

*Olitsky, N. H., \& Cosgrove, S. B. (2016). The better blend? Flipping the principles of microeconomics classroom. International Review of Economics Education, 21, 1 - 11. doi: 10.1016/j.iree.2015.10.004

Pilling-Cormick, J., \& Garrison, D. R. (2007). Self-directed and self-regulated learning: Conceptual links. Canadian Journal of University Continuing Education, 33, 13 - 33. https://doi.org/10.21225/D5S01M

Presti, C. R. (2016). The flipped learning approach in nursing education: A literature review. Journal of Nursing Education, 55, 252 - 257. https://doi.org/10.3928/01484834-20160414-03

*Ryan, M. D., \& Reid, S. A. (2016). Impact of the flipped classroom on student performance and retention: A parallel controlled study in General Chemistry. Journal of Chemical Education, 93, 13 - 23. doi: 10.1021/acsjchemed. $5 b 00717$

*Saterbak, A., Volz, T., \& Wettergreen, M. (2016). Implementing and assessing a flipped classroom model for firstyear Engineering design. Advances in Engineering Education, 5, 1 - 29.

Seery, M. K. (2015). Flipped learning in higher education chemistry: emerging trends and potential directions. Chemistry Education Research and Practice, 16, 758 - 768. doi: 10.1039/C5RP00136F 
*Shiau, S., Kahn, L. G., Platt, J., Li, C., Guzman, J. T., Kornhauser, Z. G., Keyes, K. M., \& Martins, S. S. (2018). Evaluation of a flipped classroom approach to learning introductory epidemiology. Bmc Medical Education, 18, 1 - 8. doi: 10.1186/s12909-018-1150-1

Shyr, W. J., \& Chen, C. H. (2018). Designing a technology-enhanced flipped learning system to facilitate students' self-regulation and performance. Journal of Computer assisted learning, 34, 53 - 62. doi:10.1111/jcal.12213

Stern, J. M., \& Simes, R. J. (1997). Publication bias: evidence of delayed publication in a cohort study of clinical research projects. BMJ, 315, 640 - 645. https://doi.org/10.1136/bmj.315.7109.640

*Tang, F., Chen, C., Zhu, Y., Zuo, C. G., Zhong, Y. M., Wang, N., Zhou, L. J., Zou, Y. X., \& Liang, D. (2017). Comparison between flipped classroom and lecture-based classroom in ophthalmology clerkship. Medical Education Online, 22. doi:10.1080/10872981.2017.1395679

*Tangiisuran, B., Tye, S. C., \& Tan, K. W. (2017). Implementation and assessment of flipped classroom learning on medication distribution system to pharmacy undergraduates. Pharmacy Education, 17, 109 - 114.

Tangney, S. (2014). Student-centred learning: a humanist perspective. Teaching in Higher Education, 19, 266 - 275. doi: 10.1080/13562517.2013.860099

Taylor, J. A. (2013). What is student centredness and is it enough? International Journal of the First Year in Higher Education, 4, 39 - 48. doi: 10.5204/intjfyhe.v4i1.168

*Thai, N. T. T., De Wever, B., \& Valcke, M. (2017). The impact of a flipped classroom design on learning performance in higher education: Looking for the best "blend" of lectures and guiding questions with feedback. Computers \& Education, 107, 113 - 126. doi: 10.1016/j.compedu.2017.01.003

*Tune, J. D., Sturek, M., \& Basile, D. P. (2013). Flipped classroom model improves graduate student performance in cardiovascular, respiratory, and renal physiology. Advances in Physiology Education, 37, 316 - 320. doi: 10.1152/advan.00091.2013

Uskoković, V. (2018). Flipping the flipped: the co-creational classroom. Research \& Practice in Technology Enhanced Learning, 13, 1 - 24. https://doi.org/10.1186/s41039-018-0077-9

Weber, R. P. (1990). Basic content analysis. Newbury Park, CA: SAGE Publications.

*White, P. J., Naidu, S., Yuriev, E., Short, J. L., McLaughlin, J. E., \& Larson, I. C. (2017). Student engagement with a flipped classroom teaching design affects Pharmacology examination performance in a manner dependent on question type. American Journal of Pharmaceutical Education, 81. https://doi.org/10.5688/ajpe5931

*Wozny, N., Balser, C., \& Ives, D. (2018). Evaluating the flipped classroom: A randomized controlled trial. Journal of Economic Education, 49, 115 - 129. doi: 10.1080/00220485.2018.1438860

*Wu, W.-C. V., Jun, S. C. H., \& Yang, J. C. (2017). Creating an online learning community in a flipped classroom to enhance EFL learners' oral proficiency. Journal of Educational Technology \& Society, 20, 142 - 157.

Yilmaz, R. (2017). Exploring the role of e-learning readiness on student satisfaction and motivation in flipped classroom. Computers in Human Behavior, 70, 251 - 260. doi: 10.1016/j.chb.2016.12.085

*Yong, D., Levy, R., \& Lape, N. (2015). Why no difference? A controlled flipped classroom study for an introductory Differential Equations course. Primus: Problems, Resources \& Issues in Mathematics Undergraduate Studies, 25, 907 - 921. doi:10.1080/10511970.2015.1031307

*Zeng, R., Xiang, L. R., Yue, R. Z., Zeng, J., Wan, X. H., \& Zuo, C. (2017). Friend or foe? Flipped classroom for undergraduate Electrocardiogram learning: A randomized controlled study. BMC Medical Education, 17, 53 - 61. doi: 10.1186/s12909-017-0881-8. 
Appendix 1 - Articles selected for review

\begin{tabular}{|c|c|c|c|c|c|}
\hline & Author & Site & Level & Method & Learning outcome \\
\hline 1 & Anderson et al. (2017) & USA & Graduate & Controlled experiment & Positive \\
\hline 2 & Asiksoy \& Ozdamli (2016) & Turkey & Undergrad & Controlled experiment & Positive \\
\hline 3 & Balaban, Gilleskie, \& Tran (2016) & USA & Undergrad & Quasi experiment & Positive \\
\hline 4 & Baytiyeh \& Naja (2017) & Lebanon & Undergrad & Quasi experiment & Mixed \\
\hline 5 & Boeve et al. (2017) & Netherlands & Undergrad & Quasi experiment & Positive \\
\hline 6 & Burgoyne \& Eaton (2018) & Canada & Undergrad & Quasi experiment & Mixed \\
\hline 7 & Butzler (2016) & USA & Undergrad & Quasi experiment & No difference \\
\hline 8 & Butzler (2016) & & & & No difference \\
\hline 9 & Cabi (2018) & Turkey & Undergrad & Controlled experiment & No difference \\
\hline 10 & Cakiroglu \& Ozturk (2017) & Turkey & Undergrad & Repeated measures & Positive \\
\hline 11 & Carter, Carter, \& Foss (2018) & USA & Undergrad & Quasi experiment & Positive \\
\hline 12 & Chen \& Chang (2017) & Taiwan & Mixed & Repeated measures & Positive \\
\hline 13 & Chis, Moldovan, Murphy, Pathak, \& Muntean (2018) & Ireland & Undergrad & Repeated measures & No difference \\
\hline 14 & Chis, Moldovan, Murphy, Pathak, \& Muntean (2018) & & & & Positive \\
\hline 15 & Chutinan, Riedy, \& Park (2018) & USA & Undergrad & Quasi experiment & Mixed \\
\hline 16 & Cotta, Shah, Almgren, Macías-Moriarity, \& Mody (2016) & USA & Undergrad & Quasi experiment & Positive \\
\hline 17 & Cronhjort, Filipsson, \& Weurlander (2018) & Sweden & Undergrad & Quasi experiment & Positive \\
\hline 18 & Dehghanzadeh \& Jafaraghaee (2018) & Middle East & Undergrad & Quasi experiment & Positive \\
\hline 19 & Eichler \& Peeples (2016) & USA & Undergrad & Quasi experiment & Positive \\
\hline 20 & Elmaadaway (2018) & Saudi Arabia & Undergrad & Controlled experiment & Positive \\
\hline 21 & Entezari \& Javdan (2016) & USA & Undergrad & Quasi experiment & Mixed \\
\hline 22 & Fautch $(2015)$ & USA & Undergrad & Quasi experiment & Positive \\
\hline 23 & Foldnes (2016) & Norway & Undergrad & Quasi experiment & No difference \\
\hline 24 & Foldnes (2016) & & & & Positive \\
\hline 25 & Goates, Nelson, \& Frost (2017) & USA & Undergrad & Controlled experiment & Negative \\
\hline 26 & González-Gómez, Jeong, Airado Rodríguez, \& Cañada-Cañada (2016) & Spain & Undergrad & Controlled experiment & Positive \\
\hline 27 & Gross, Pietri, Anderson, Moyano-Camihort, \& Graham (2015) & USA & Undergrad & Quasi experiment & Positive \\
\hline 28 & Hung $(2015)$ & Taiwan & Undergrad & Quasi experiment & Mixed \\
\hline 29 & Hung (2015) & & & & Mixed \\
\hline 30 & Jensen, Kummer, \& Godoy (2015) & USA & Undergrad & Quasi experiment & No difference \\
\hline 31 & Kim, Park, Jang, \& Nam (2017) & South Korea & Undergrad & Quasi experiment & Positive \\
\hline 32 & Koo, Demps. Farris, Bowman, Panahi, \& Boyle (2016) & USA & Graduate & Quasi experiment & Positive \\
\hline 33 & Kurt (2017) & Turkey & Undergrad & Controlled experiment & Positive \\
\hline 34 & Lax, Morris, \& Kolber (2017 & USA & Undergrad & Quasi experiment & Mixed \\
\hline 35 & Lee \& Kim (2018) & USA & Graduate & Quasi experiment & Positive \\
\hline 36 & Lee \& Wallace (2018) & South Korea & Undergrad & Quasi experiment & No difference \\
\hline
\end{tabular}




\begin{tabular}{|c|c|c|c|c|c|}
\hline & Author & Site & Level & Method & Learning outcome \\
\hline 37 & Lin \& Hwang (2018) & Taiwan & Undergrad & Quasi experiment & Positive \\
\hline 38 & Lombardini, Lakkala \& Muukkonen (2018) & Finland & Undergrad & Quasi experiment & No difference \\
\hline 39 & Lombardini, Lakkala \& Muukkonen (2018) & & & & Positive \\
\hline 40 & Muzyk, Fuller, Jiroutek, Grochowski, Butler, \& Bryon (2015) & USA & Graduate & Quasi experiment & No difference \\
\hline 41 & $\mathrm{Ng}(2018)$ & Hong Kong & Undergrad & Repeated measures & Positive \\
\hline 42 & Nielson, Bean \& Larsen (2018) & USA & Undergrad & Quasi experiment & Positive \\
\hline 43 & Olitsky \& Cosgrove (2016) & USA & Undergrad & Quasi experiment & Mixed \\
\hline 44 & Peterson (2016) & USA & Undergrad & Quasi experiment & Positive \\
\hline 45 & Ryan \& Reid (2016) & USA & Undergrad & Quasi experiment & No difference \\
\hline 46 & Saterbak, Volz, \& Wettergreen (2016) & USA & Undergrad & Quasi experiment & No difference \\
\hline 47 & Shiau et al. (2018) & USA & Graduate & Quasi experiment & No difference \\
\hline 48 & Tang et al. (2017) & Taiwan & Undergrad & Controlled experiment & Positive \\
\hline 49 & Tangiisuran, Tye, \& Tan (2017) & Malaysia & Undergrad & Repeated measures & Positive \\
\hline 50 & Thai, De Wever, \& Valcke (2017) & Vietnam & Undergrad & Controlled experiment & Positive \\
\hline 51 & Tune, Sturek, \& Basile (2013 & USA & Graduate & Quasi experiment & Positive \\
\hline 52 & White et al. (2017) & Australia & Undergrad & Correlational & Positive \\
\hline 53 & Wozny, Balser, \& Ives (2018) & USA & Undergrad & Controlled experiment & Mixed \\
\hline 54 & Wu, Jun, \& Yang (2017) & Taiwan & Undergrad & Repeated measures & Positive \\
\hline 55 & Yong, Levy, \& Lape (2015) & USA & Undergrad & Quasi experiment & No difference \\
\hline 56 & Zeng et al. (2017) & China & Undergrad & Controlled experiment & Positive \\
\hline
\end{tabular}

